\title{
O PROCESSO DE HUMANIZAÇÃO DO SISTEMA PRISIONAL BRASILEIRO
}

\section{THE PROCESS OF HUMANIZATION OF THE BRAZILIAN PRISON SYSTEM}

\author{
Jaasiel Gipson da Silva Campos ${ }^{1}$
}

RESUMO: O processo de humanização do sistema prisional brasileiro pautado nos elementos essenciais na problemática do poder de punir, conforme Foucault transferiu-se da vingança do soberano para a defesa da sociedade, o que, talvez, traz mais insegurança do que garantias, assim, o princípio da moderação demonstra ser extremamente essencial para coibir os excessos, o qual se baseia na sensibilidade do homem razoável e não no rigor da lei ou no grau de perigo do infrator que durante muito tempo foi objeto da Execução Penal contrariando os Direitos da Pessoa Humana. O objetivo será proporcionar destaque ao processo de humanização do sistema prisional brasileiro pautado nos elementos essenciais na problemática do poder de punir estatal. Para alcançar tal objetivo proposto realizar-se-á uma pesquisa pelo método dedutivo de cunho qualitativo, exploratório e bibliográfico. No Brasil, apesar das conquistas sociais insculpidas na Constituição Federal de 1988, nosso país é um dos mais injustos do mundo; por um paradoxo em decorrência de sua imensa riqueza a qual fez seu povo mais pobre e suas elites mais ricas chegarem a uma proporção de desigualdade que assombra cientistas sociais e juristas de todos os países, que prejudicam as políticas de segurança pública destinadas à questão penitenciária decorrente de características neoliberais. Mudanças radicais se fazem necessárias e com urgentes, pois o princípio da dignidade da pessoa humana deve sempre pautar as atividades voltadas para o sistema penitenciário, por ser medida assecuratória da obrigação do Estado em garantir um patamar mínimo de forma humanizada a população prisional brasileira.

Palavras-chave: População Prisional. Humanização. Sistema Prisional. Direitos Humanos.
ABSTRACT: The process of humanization of the Brazilian prison system based on the essential elements in the problematic of the power to punish, as Foucault transferred from the revenge of the sovereign to the defense of society, which perhaps brings more insecurity than guarantees, thus, the principle of moderation proves to be extremely essential to curb excesses, which is based on the reasonable man's sensitivity and not on the rigor of the law or the degree of danger of the offender who for a long time was the subject of Criminal Execution contrary to the Rights of the Human Person. The objective will be to highlight the process of humanization of the Brazilian prison system based on the essential elements in the problem of the State's power to punish. In order to reach this proposed objective, a qualitative, exploratory and bibliographic research will be carried out using the deductive method. In Brazil, despite the social achievements inscribed in the Federal Constitution of 1988, our country is one of the most unjust in the world; by a paradox as a result of its immense wealth which has made its poorer people and their wealthier elites reach a proportion of inequality that haunts social scientists and jurists of all countries, which undermine public security policies aimed at the penitentiary issue arising of neoliberal characteristics. Radical changes are necessary and urgent, since the principle of human dignity must always guide activities aimed at the penitentiary system, since it is an assecuratory measure of the State's obligation to guarantee a minimum humanized level of the Brazilian prison population.

Keywords: Prison Population. Humanization. Prison System. Human rights. 


\section{INTRODUÇÃO}

Com a passagem do absolutismo para o iluminismo, a sociedade em detrimento de alguns direitos personalíssimos passou ao Estado o direito de punir, que deve ser exercido nos termos da lei e, certamente, não podendo existir o prazer de punir pela sede de vingança estatal. Michel Foucault (2007) em estudos sobre o poder de punir já lesionava que é preciso distinguir a confrontação física entre o condenado e o Estado.

Com o surgimento do sistema carcerário, ocorreu uma evolução no poder punitivo do Estado que deixou de aplicar penas capitais e passou a realizar penas restritivas de liberdade, o qual substituiu os excessos nas formas de punir outrora sempre ligados ao soberano que permitia ao poder disciplinar realizar atrocidades de banimento e métodos punitivos ligados à vingança utilizando suplícios aos infratores.

Michel Foucault (2007) realizou estudos sobre o processo punitivo que era ligado ao castigo, dessa forma com o sistema carcerário altera-se para uma técnica penitenciária ligada ao adestramento dos condenados com o objetivo de ressocialização e um retorno digno a sociedade pelo estudo, trabalho e da religião dentro das prisões.

Ocorreu no século XX, uma significante preocupação quanto aos problemas da Execução Penal, pois adequações nas leis deveriam ser realizadas com o intuito de modernizar o processo da pena, fundada em uma unificação orgânica em decorrência de tratamentos reeducativos, como também, como organizar as penitenciárias.

No Brasil, os estudos ligados a ressocialização e educação dos detentos emergem apenas em 1890, com a criação do regime penitenciário correcional, pois até a mencionada data as penas somente destinavam-se às punições voltadas ao sofrimento máximo, geralmente, aplicadas de forma cruel, sem qualquer preocupação com a humanidade dos sentenciados.

Com o advento dos direitos humanos, surge o princípio da moderação das penas que tem como característica principal a vedação de abusos, torturas e arbítrios, quando da aplicação de qualquer penalidade estabelecida, que deverá ser respeitada e pautada em princípios humanos e garantias constitucionais ao homem comum.

Dessa forma, os estabelecimentos prisionais devem proporcionar e adequar-se ao desenvolvimento da personalidade dos apenados, pois se continuarem a quebrar regras dentro do sistema prisional qualquer ressocialização estará fadada ao fracasso.

\section{OBJETIVOS}

Proporcionar destaque ao processo de humanização do sistema prisional brasileiro pautado nos elementos essenciais na problemática do poder de punir estatal;

Conjecturar possibilidades de melhorias no processo de ressocialização dos apenados em decorrência de trabalhos, estudos e religião dentro do sistema carcerário; e Analisar a utilização de métodos militares de adestramento pessoal pautados na disciplina aos encarcerados brasileiros.

\section{METODOLOGIA}

O presente projeto foi realizado por meio do método dedutivo, que parte da compreensão da regra geral para então compreender os casos específicos, por ser um processo de análise de informações que nos leva a uma conclusão, ou seja, usa-se da dedução para encontrar o resultado final. (VERGARA, 2010)

O trabalho se realizará com abordagem de cunho qualitativo, pois 
segundo Lakatos e Marconi (2004, p. 269), este tipo de metodologia analisa e interpreta aspectos mais profundos, demonstrando a complexidade do comportamento humano, ou seja, proporciona uma análise mais detalhada sobre hábitos e tendências do ser humano.

Com base nos objetivos a pesquisa será exploratória. Tendo como objetivo proporcionar maior familiaridade com o problema, com vista a torná-lo mais explicito ou construir hipóteses com o aprimoramento de ideias e descoberta de intuições.

Em relação aos procedimentos técnicos a pesquisa será bibliográfica, pois na visão de Lakatos e Marconi (2004), abrange toda a bibliografia já tornada pública em relação ao tema estudado, desde as publicações avulsas, boletins, jornais, revistas, livros. Sua finalidade é colocar o pesquisador em contato direto com tudo o que foi escrito, dito ou filmado sobre determinado assunto para um melhor atendimento da sociedade acadêmica em geral.

Esta pesquisa

marca bibliograficamente as visões de autores ligados ao Direito Penal, Direito Processual Penal, Direitos Humanos e a Segurança Pública Nacional, os quais procuram mostrar de que forma podemos discutir o processo de humanização do sistema prisional brasileiro pautado na problemática do poder de punir, otimizando sua aplicabilidade em relação aos seus efeitos ressocializadores.

\section{RESULTADOS \\ E PRELIMINARES}

Ao pensar em melhorias no sistema prisional existe a necessidade de alterar os entendimentos do poder de punir que deverão ser otimizados para uma aplicabilidade mais eficiente em relação aos seus efeitos sociais e humanos.

A evolução da sociedade é marcada historicamente pelas atrocidades dispensadas a quem infringiam as regras impostas pelo Estado, visto que não existia nenhum instrumento que minimizar-se a vontade geral e feroz de punir os malfeitores.

Cesare Beccaria (1999), em 1764, já questionava qual seria o direito que os homens se reservavam de trucidar seus próximos ou semelhantes, tendo como resposta absurda a vontade geral de simplesmente se vingar dos graves ou ínfimos delitos.

Cézar Roberto Bitencourt (2017), diz que mesmo com o desaparecimento dos suplícios e o surgimento de uma punição velada na arte de fazer sofrer, os avanços da humanidade, o direito de punir transfere-se da vingança do soberano para a defesa da sociedade, o que gerou mais insegurança social.

Assim surge, na doutrina norteamericana e na alemã, no século XVIII, o princípio da moderação das penas que demonstra ser extremamente essencial na proibição do excesso, baseada na sensibilidade humana, em sua razoabilidade e não no rigor legislativo, como também, descartando a periculosidade do infrator. Nas palavras de Michel Foucault (2007) o princípio da moderação das penas serve:

Para ser útil, a pena deve ser calculada não
em função do delito, mas de possível
reincidência. Visar não à ofensa passada, mas
a desordem futura. Fazer de tal modo que o
criminoso não possa ter vontade de
recomeçar.

Já Cesare Beccaria (1999) adota a teoria que se penas iguais são aplicadas a dois delitos que afetam de maneira distinta a sociedade, não haveria óbices que impediriam práticas de delitos mais gravosos.

Por isso, não se pode dizer que a proporcionalidade das penas se destina à distribuição igual de castigo, baseada na ideia de suavização. 
Deve-se ter noção de que a proporcionalidade está tanto na regra da quantidade mínima como no limite da penalidade estrita. $\mathrm{O}$ princípio da moderação das penas estabelece medidas adequadas ao caso concreto, uma maior eficácia ao sistema punitivo, o qual resultará em medida suficiente à inibição ocorrências de novos crimes.

\section{DIREITOS HUMANOS PROTEGIDOS AOS APENADOS}

Os direitos humanos inerentes a qualquer pessoa devem ser sempre respeitados e a individualização das penas é um significativo exemplo desses direitos subjetivos o qual considera as características do fato ocorrido e de cada criminoso, adotando-se uma punição justa, sem excessos, abusos, torturas e nem carências.

A mudança de foco sobre o condenado, que durante muito tempo é objeto da Execução Penal, ocorre através do estabelecimento dos Direitos da Pessoa Humana com os objetivos de reformar o delinquente e desestimular a prática de novos delitos.

Por sua característica de Estado Democrático de Direito, prevista na Carta Magna, o Brasil tem o dever de concretizar os direitos e deveres dos apenados, assim a Lei de Execução Penal, garante todos os direitos não atingidos pela sentença que impõe ao condenado, no início da pena, a ciência das normas disciplinares, seus direitos, limitações e deveres. O artigo 41 da Lei de Execução Penal (BRASIL, 1984), diz que:

Art. 41 - Constituem direitos do preso:

I - alimentação suficiente e vestuário;

II - atribuição de trabalho e sua remuneração;

III - Previdência Social;

IV - constituição de pecúlio;

V - proporcionalidade na distribuição do tempo para o trabalho, o descanso e a recreação;
VI - exercício das atividades profissionais, intelectuais, artísticas e desportivas anteriores, desde que compatíveis com a execução da pena;

VII - assistência material, à saúde, jurídica, educacional, social e religiosa;

VIII - proteção contra qualquer forma de sensacionalismo;

IX - entrevista pessoal e reservada com o advogado;

X - visita do cônjuge, da companheira, de parentes e amigos em dias determinados;

XI - chamamento nominal;

XII - igualdade de tratamento salvo quanto às exigências da individualização da pena;

XIII - audiência especial com o diretor do estabelecimento;

XIV - representação e petição a qualquer autoridade, em defesa de direito;

$\mathrm{XV}$ - contato com o mundo exterior por meio de correspondência escrita, da leitura e de outros meios de informação que não comprometam a moral e os bons costumes.

XVI - atestado de pena a cumprir, emitido anualmente, sob pena da responsabilidade da autoridade judiciária competente.

Parágrafo único. Os direitos previstos nos incisos $\mathrm{V}, \mathrm{X}$ e $\mathrm{XV}$ poderão ser suspensos ou restringidos mediante ato motivado do diretor do estabelecimento.

Nos dizeres de Rizzatto Nunes (2010), trata-se de direitos específicos que se somam aos quais os sentenciados já são titulares na sua própria condição de cidadãos, como o direito à vida, o direito à integridade física e moral, o direito de consciência e de convicção religiosa, o direito ao sigilo de correspondência e das comunicações telegráficas, de dados e telefônicas, o direito à assistência judiciária e o direito à indenização por erro judiciário ou por prisão além do tempo fixado na sentença, todos estes devidamente previstos no Art. 5o, da Constituição Federal (BRASIL, 1988).

Para Luís Francisco Carvalho Filho (2002), a entrega de gêneros alimentícios aos sentenciados tem sido tratada como um direito incontestável dos presos, permitida em quase toda a totalidade dos estabelecimentos prisionais brasileiros, mesmo sendo um risco a segurança dos 
presídios; já que a grande maioria das armas e aparelhos celulares que ingressam no sistema prisional são trazidos nesses alimentos sem falar que coloca em risco a higiene dos presídios.

Os presos estrangeiros possuem direitos idênticos aos presos brasileiros, posto que a Constituição (BRASIL, 1988), em seu artigo $5^{\circ}$ determina que todos são iguais perante a lei. $\mathrm{Na}$ prática, a maior dificuldade do sentenciado estrangeiro é conseguir adquirir os benefícios do livramento condicional e indulto, pois o estrangeiro condenado no Brasil não pode permanecer morando no país. (FILHO, 2002)

A Lei de execuções penais (BRASIL, 1984), em seu Artigo 88, determina que deva ser reservado a cada preso um espaço de seis metros quadrados, situação longínqua da realidade atual, onde os condenados cumprem pena em espaços de apenas trinta centímetros quadrados, onde se revezarem para dormir ou amarram-se nas grades, já que o espaço interno da cela não permite que todos se deitem ao mesmo tempo.

\section{Propostas de Ressocialização Presidiários}

Uma das propostas de ressocialização dos apenados é por meio do trabalho nos presídios, o qual seguiu historicamente na conceituação da pena privativa de liberdade e apresenta três grandes estágios. No primeiro, o trabalho era entendido como um elemento fundamental para a regeneração moral e normatização social do apenado, como uma política positiva. No segundo estágio, o trabalho era entendido como elemento agravante da punição em decorrência da concepção de trabalhos forçados.

No terceiro estágio, o trabalho visa dotar ao preso competências para que possa desenvolver uma atividade produtiva e econômica que facilite a sua reinserção social. O trabalho prisional, dentro de uma visão mais realista, passa a desempenhar dois papéis distintos, embora totalmente interligados.

De um lado, ele serve para reduzir os conflitos do recluso durante o tempo em que está preso minorando os efeitos prejudiciais do estabelecimento prisional. Por outro lado, o trabalho pretende contribuir para a sua real ressocialização, embora reconhecendo que nem sempre isso é possível.

A falta de políticas públicas impede a construção de penitenciárias para a devida execução penal e, consequentemente, para que possam proporcionar melhores condições de vida ao preso. Paulo Bonavides (2018) assinala que socialmente, o Brasil é o País mais injusto do mundo; por um paradoxo, sua riqueza fez seu povo mais pobre e suas elites mais ricas numa proporção de desigualdade assombrosa.

As políticas de segurança pública destinadas à questão penitenciária têm por caracterização uma política neoliberal em seu último grau de consolidação e, consequentemente, as penitenciárias não prescindem de socorro aos mais carentes.

Dessa maneira, para Júlio Fabbrini Mirabete (2017), a execução penal estará subordinada aos princípios neoliberais e a massa carcerária neste contexto é personificada como grupo marginal carente, por se tratar de uma minoria improdutiva que não realizam as contrapartidas prestadas pelos programas públicos, por isso os condenados ficam a mercê da caridade desumana do Estado.

A efetivação da Lei de Execução Penal (BRASIL, 1984) depende diretamente do financiamento do Estado, o qual, por sua vez, prioriza recursos para parcelas mais significativas de eleitores, o que não é o caso do presidiário, já que ele tem os seus direitos 
políticos cassados com a condenação. brasileiro.

(MIRABETE, 2017)

Ante a ausência de políticas sérias e investimentos no sistema penitenciário brasileiro, as velhas e insalubres instalações penitenciárias, além daquelas superlotadas, efetivamente não atingem a ressocialização do indivíduo, o qual sequer possuía socialização, por já ser, anteriormente ao cárcere, excluído pelo poder público.

Recolhem-se os presos a locais análogos aos calabouços antigos, aglomerando-os em cubículos e retirando-os a dignidade.

No recinto das prisões, aspira-se um ar verdadeiro terror, repressão e constrangimento, agravado pela arquitetura ultrapassada dos presídios com celas úmidas, de tetos elevados, pequenas, sem luminosidade e ausência total de ventilação, num ambiente propício e facilitador do homossexualismo e dos constantes assaltos sexuais.

\section{Ressocialização do Apenado pelo Adestramento Militar}

Ao ingressar em um presídio brasileiro, o sentenciado é despido de sua aparência usual. É despojado de seus pertences pessoais, recebe um uniforme padronizado de utilização obrigatória. Seu nome é substituído por um número, denominado matrícula. O seu cabelo é raspado. É privado de toda e qualquer comodidade material, recebendo somente o necessário para a sua higiene pessoal.

Realizando uma analogia com as escolas de formação de militares das Forças Armadas e auxiliares os alunos desses centros de formação perdem toda a sua subjetividades por um determinado tempo e praticamente são obrigados e seguir rigorosamente todas as obrigações dos apenados, com a diferença que irão estudar e trabalhar para garantir a soberania do estado
Dessa forma, uma possiblidade de ressocialização dos presos no sistema carcerário brasileiro seria o adestramento dos apenados com técnicas militares voltadas para a disciplina, respeito às regras da lei, do trabalho profissionalizante e de estudos para uma verdadeira socialização pessoal.

Erwing Goffman (2005), em sua obra intitulada Manicômios, Prisões e Conventos, já demonstrava o caráter arrasador dos presídios, quando desconsideram a personalidade de cada um dos internos, englobando-os como se fossem todos iguais, possuindo, por isso, as mesmas necessidades. Segundo o referido autor:
Uma instituição total pode ser definida como um local de residência, estudo e trabalho onde um grande número de indivíduos com situação semelhante, separados da sociedade mais ampla por considerável período de tempo, levam uma vida fechada e formalmente administrada.

Demonstrando o conflito que existe na sistematização das ações de toda e qualquer pessoa que esteja internada em um estabelecimento social, tal como a prisão, Erwing Goffman (2005) aduz ainda que:
Ora, se qualquer estabelecimento social pode ser considerado como um lugar onde sistematicamente surgem suposições a respeito do eu, podemos ir adiante e considerar que é um local onde tais suposições são sistematicamente enfrentadas pelo participante. Adiantar-se nas atividades prescritas, ou delas participar segundo formas não-prescritas ou por objetivos não- prescritos, é afastar-se do eu oficial e do mundo oficialmente disponível para ele. Prescrever uma atividade é prescrever um mundo; eludir uma prescrição pode ser eludir uma identidade.

Dessa maneira, para Alexandre de Moraes (2016), quando existem atividades pré-estabelecidas voltadas para indivíduos em geral, haverá consonância de comportamento sem existir perda da identidade destes indivíduos.

É nesse contexto que surgem os problemas, já que os apenados que não 
cooperam com a instituição prisional passam a desenvolver um ajustamento secundário que é o emprego de meios ilícitos para se escapar do dever-ser, ou daquilo que a organização supõe que se deve fazer ou obter. (MORAES, 2016)

Assim mesmo levando em consideração a possiblidade de utilização do adestramento militar nos presídios, para uma verdadeira humanização da pena é fundamental o respeito à individualidade do detento, estimulando-lhe a autoconfiança e mostrando que ele é capaz para fazer algo positivo. Com isso, é certo que estará sendo dispensado ao preso um tratamento digno em todos os sentidos.

\section{CONSIDERAÇÕES FINAIS}

O estudo mostra-nos o quão distante o sistema prisional brasileiro está do ideal humanitário. Mudanças radicais e imediatas são necessárias, pois a cada dia que se passa a revolta humana dos encarcerados só tendem a aumentar nessas instituições.

Modernizações nas arquiteturas penitenciárias; melhorias na assistência médica, psicológica e social; ampliações nos projetos visando o trabalho dos apenados para ocupação de suas mentes e dos seus espíritos; preparo e acompanhamento na reintegração social do detento; dentre outras medidas são imprescindíveis para que as mudanças no sistema prisional brasileiro possam ter início.

O princípio da dignidade da pessoa humana deve sempre pautar as atividades voltadas para o sistema penitenciário, haja vista ser ele medida assecuratória da obrigação do Estado em garantir à pessoa humana um patamar mínimo de recursos, capaz de prover-lhe a subsistência.

Sendo assim, foram proporcionadas algumas medidas para que o detento possa se ocupar durante o cumprimento de sua pena, sem que seja agredida a sua dignidade humana. Dentre tais medidas, as que demonstram ser, em um primeiro momento, mais eficazes são aquelas que dizem respeito ao trabalho, a educação e ao respeito à individualidade do detento, para tanto, é fundamental que o Estado priorize a sua adequada prestação de serviços pautada na dignidade da pessoa humana.

\section{REFERÊNCIAS BIBLIOGRÁFICAS}

BECCARIA, Cesare. Dos delitos e das penas.

1. ed. São Paulo: Edipro, 1999.

BITENCOURT, Cézar Roberto. Falência da pena de prisão. $5^{\circ}$ ed. Revista dos Tribunais. São Paulo: 2017.

BONAVIDES, Paulo. Ciência Politica. 25 Ed. Saraiva. 2018

BRASIL. Constituição (1988). Constituição da República Federativa do Brasil. Brasília, DF: Senado, 1988.

\section{Lei $\mathrm{n}^{\circ} 7.210$, de 11 de julho de}

1984. Institui a Lei de Execução Penal.

FILHO, Luís Francisco Carvalho. A prisão. São Paulo: Publifolha, 2002.

FOUCAULT, Michel. Vigiar e punir. 34. ed. São Paulo: Vozes, 2007.

GOFFMAN, Erwing. Manicômios, prisões e conventos. 7.ed. São Paulo: Perspectiva, 2005.

MARCONI, Marina de Andrade; LAKATOS, Eva Maria. Metodologia do trabalho científico. 7. ed. São Paulo: Atlas, 2009.

MIRABETE, Júlio Fabbrini. Execução Penal. São Paulo: Atlas, 2017.

MORAES. Alexandre de. Direitos humanos fundamentais. 11 ed. São Paulo: Atlas, 2016. NUNES, Rizzatto. O princípio constitucional da dignidade da pessoa humana. São Paulo: Saraiva, 2010.

VERGARA, Sylvia Constant. Projetos e Relatórios de Pesquisa em Administração, $12^{\mathrm{a}}$ ed., São Paulo: Atlas, 2010. 